\title{
LA COMUNICACIÓN EDUCATIVA
}

\section{Autores}

ELISA TORRE RAMOS

DE EXPRESTÓN CORPORAL DE LA FACULTAD DE DAD DE GRANADA.

\section{Introducción}

Entendemos por comunicación el proceso mediante el cual dos o más personas transfieren e intercambian información (conocimientos, sentimientos, ideas), para lo cual se precisa de un emisor o persona que estructuray transmite el mensaje, el canal o medio a través de cual se difunde el mismo, el código o sistema de señales en los que se halla representado y, por último, el recep tor o persona que capta el mensaje, lo decodifica y lo interpreta, sin olvidarnos de esa información de retorno que, de manera implícita o explícita, éste le ofrece a emisor acerca de cómo ha interpretado el mensaje trasmitido por el mismo.

El dominio de este proceso es de suma importancia para facilitar el entendimiento entre las personas en diferentes situaciones, pero qué duda cabe que, en determinados ámbitos, su importancia es crucial; concre tamente, en lo que al educativo se refiere, la comunicación es la que nos brinda y facilita el intercambio de mensajes formativos en el proceso de enseñanza-aprendizaje. Sin embargo, aunque aparentemente pueda re sultar algo tan sencillo como dar por sentado que el hecho de dominar determinados conocimientos teóricos o prácticos, ya nos concede licencia para desenvolvernos en dicho ámbito, no debemos olvidar que, con relativa frecuencia, se manifiestan múltiples problemas que atienden principalmente al dominio, por parte del emisor, de determinadas habilidades comunicativas relacionadas con lo que dice (lenguaje verbal), con el cómo lo dice (lenguaje paraverbal y lenguaje corporal), y con el uso y estructuración del entorno (espacio y objetos) en el que se transmite ese mensaje. Por ello, y siendo muy conscientes de que la verdadera esencia de la educación está en la comunicación, resulta paradójico comprobar cómo, en determinadas facultades, algo que re sulta tan útil profesionalmente carece de una forma-
Escucho con mis ojos y leo el silencio, en la musicalidad de la expresividad del gesto, me ofrezco una interpreación de la gente, de la situación, de la cultura y de ellos mismos, que me sirve de espejo para comprender la vida, la mía (Laffereire,1997)

ción específica, equitativa y unánime, que nos oriente y acerque a la pedagogía de la comunicación. De este modo, desechamos la idea de que el hacerse entender es cuestión de "arte o talento", al que sólo acceden unos privilegiados, y abogamos por un proceso de formación que posibilite "una mayor facilidad de palabra y fluidez oral", "una mayor locuacidad" "un mayor número de palabras "une fluyar de manera natural", "una mayor ayor capacidad para estructurar el mensaje y transmitirlo", "un mayor potencial expresivo", "una mayor capacidad para percibir e interpretar el continuo feed-back que le ofrece el alumnado" $y$, en definitiva, una mayor calidad docente. Actualmente en los planes de estudios de formación del profesorado de determinados países, no sólo se trabaja en pro de estas capacidades, junto con el dominio de determinadas técnicas e instrumentos, sino que, ade más, se le exige acreditar ciertas competencias comunicativas para poder acceder al ámbito educativo.

El estudio de la comunicación ha dado lugar a diferentes clasificaciones o taxonomías, no siempre compartidas y aceptadas por la dificultad que entraña se parar lo verbal de lo noverbal dentro de las cuales, una

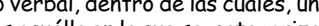
egorizan todos los aspectos lingüísticos del discurso como "comunicación verbal" y, el resto, es decir, los aspectos no lingüísticos del lenguaje (entonación, ritmo de elocución etc.), el lenguaje corporal, la apariencia física, el contacto corporal y la estructuración del entorno, como elementos de la "comunicación no verbal". Nosotros nos hemos atrevido a subdividir la comunicación en cuatro grandes bloques que, aunque en definitiva se mantienen íntimamente relacionados, cuentan ya con tal grado de identidad, que existen diferentes disciplinas que se encargan de su estudio: la comunicación verbal (la pala bra) analizada desde la lingüística la comunicación paraverbal (la voz) abordada desde la paralingüística el lenguaje del cuerpo (gestos y posturas) del que se ocupa la quinésica, y el uso y estructuración del espacio (espacio y objetos) que corresponde a la proxémica. 
Retos. Nuevas tendencias en

Educación Física, Deporte y Recreación

2002, $n^{\circ} 3$, pp. 37-43
Federación Española de Asociaciones de Docentes de Educación Física (FEADEF)

ISSN edición impresa: 1579-1726

Por todo ello, nuestro principal ob jetivo se va a centrar en analizar de terminadas capacidades comunicativas con las que debe contar el profesorado atendiendo a estas cuatro grandes categorías, sin obviar el hecho de que, tal y como apuntan algunos estuMehrabian (1972) y Nierenberg y Gschwander (1989), en determinados momentos, como por ejemplo en el inicio de una conferencia ante un auditorio o incluso en el transcurso de la misma la comunicación paraverbal yel lenguaje corporal impactan mucho más (un 38\% y un $55 \%$ respectivamente constituyendo casi el $93 \%$ del men saje), que las palabras utilizadas (que tan sólo suponen un $7 \%$ ), de lo cual se deduce, que el quid de la cuestión no nido del mer de aliarlo al cuerpo, a la voz y al espacio, para transmitir más y mejor.

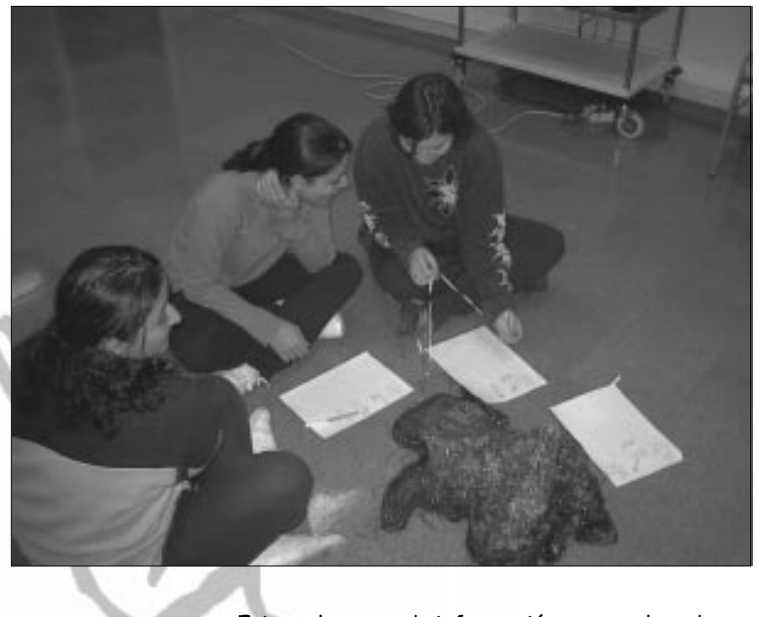

Evitar el exceso de información por resultar demasiado compleja para el nivel del alumnado o por pecar de superflua.

\section{La comunicación verbal}

Partiendo de los elementos necesarios en toda comunicación (emisor, receptor, canal, código y mensaje) y centrándonos en el emisor que utiliza como herramienta comunicativa la palabra, y más concretamente, en el profesorado que diariamente se enfrenta a un alumnado en un aula, nuestros principales objetivos son los de analizar aquellas premisas que hacen posible que el mensaje llegue con la mayor claridad y precisión posible, resaltlegue con la mayor claridad y precisión posible, resaltando algunas estrategias de intervención que, en cier-
ta medida, contribuyan al alcance de un cierto grado de competencia educativa.

Por eso, nuestra primera intención es la de asegurar, por parte del hablante, una cierta coherencia entre lo que dice y lo que se quiere decir, puesto que, en ocasiones, existen ciertas discrepancias que se pueden solventar respondiendo a las siguientes preguntas: ¿qué es exactamente lo que quiero contar y cómo lo voy a hacer?, lo cual equivale a establecer previamente un plan de acción que recoja el significado explícito del mensaje, de manera deliberada y consciente, y que se podría resumir en las siguientes premisas y estrategias de intervención:

1. Determinar lo que se quiere comunicar estructurando el mensaje de tal forma que facilitemos la comprensión del mismo por parte del alumnado, para lo cual resulta de gran ayuda:

- Tener muy claros los objetivos de la comunicación.

- Organizar la información de tal manera que exista siempre un hilo conductor que ayude por un lado al alumnado a progresar en la asimilación de los conceptos partiendo de los que ya posee, y al interlocutor, por otro, para que no pierda la idea principal, ni divague en exceso durante su discurso.

- Utilizar recursos visuales (transparencias, texto. etc.) que sirvan de guía durante la exposición.

Redundar en los aspectos esenciales del mensaje aclarando los conceptos o términos de difícil comprensión, al igual que hacemos al subrayar en el texto escrito los conceptos relevantes.

Y por último, resumir las ideas esenciales en pocas palabras y establecer algunas conclusiones.

2. Seleccionar el código o los signos que van a facilitar la transmisión y comprensión del mensaje de la manera más adecuada. De entre ellos los más uti-

lizados en este tipo de comunicación son los símbolos lingüísticos orales que ambos, emisor y receptor, deberán compartir y dominar, sin olvidarnos de que aún hablando el mismo idioma o lengua, las distintas especialidades del lenguaje (lenguaje coloquial, lenguaje científico, jurídico, etc.) cobran sentido cuando nos adaptamos al contexto o situación en el que nos desenvolvemos, por lo que deberemos valorar, a priori, la materia o tema del discurso, el estilo o las exigencias formales y la terminología empleada. No obstante, contamos también con otros signos que apoyan y refuerzan el contenido del mensaje como los iconos o la simbología no lingüística, que en muchas ocasiones, resultan mucho más universales que los anteriores, ahorrándonos un cierto esfuerzo.

3. Elegir el medio o canal a través del cual se produce el mensaje, determinando qué canales naturales (visual, auditivo, etc.) o artificiales (teléfono, ordenador, fax, etc.) resultan más apropiados atendiendo al contexto, objetivos y contenidos del mensaje, así como a las características del receptor. El canal que predomina fundamentalmente en este tipo de comunicación es el auditivo, sin menospreciar al resto, como por ejemplo el visual no sólo por el papel que pueden desempeñar complementando el mensaje sino porque, en ocasiones, la entonación del mismo o el lenguaje gestual lo contradicen (mensajes verbales que resaltan aspectos conceptuales impor- 
tantes y que se exponen utilizando un tono de voz bajo y una actitud retraída), dificultando la interpretación por parte del receptor. Por otro lado, resulta de suma importancia reconocer que cuando saturamos en exceso el canal que elegimos para transmitir la información, ya sea visual (exceso de imágenes) o auditivo (hablar demasiado deprisa), provocamos la fatiga y el receptor termina por desconectar.

Además, nos gustaría resaltar que, independiente mente del significado explícito del mensaje, éste siempre va acompañado de uno implícito que, en ocasiones, en vez de reforzarlo le resta credibilidad e interés, y que se manifiesta muy claramente en determinadas situaciones en las que el emisor muestra falta de confianza en sí mismo, claramente visible en situaciones de inexperiencia, así como en el mensaje que envía, bien porque lo desconoce y no lo domina, bien porque no le otorga la valía que se merece.

Por último, y entendiendo la comunicación como un proceso cíclico en el que el emisor recibe continuamen te información del receptor acerca de cómo ha inter pretado el mensaje, hemos de valorar ciertas capacidades, por encima de otras, como la de ser capaz de crear un clima afectivo distendido, en el que el receptor se encuentre con libertad para intercambiar información así como el dominio de ciertas habilidades de observación que le permitan captar el contenido implícito de mensaje.

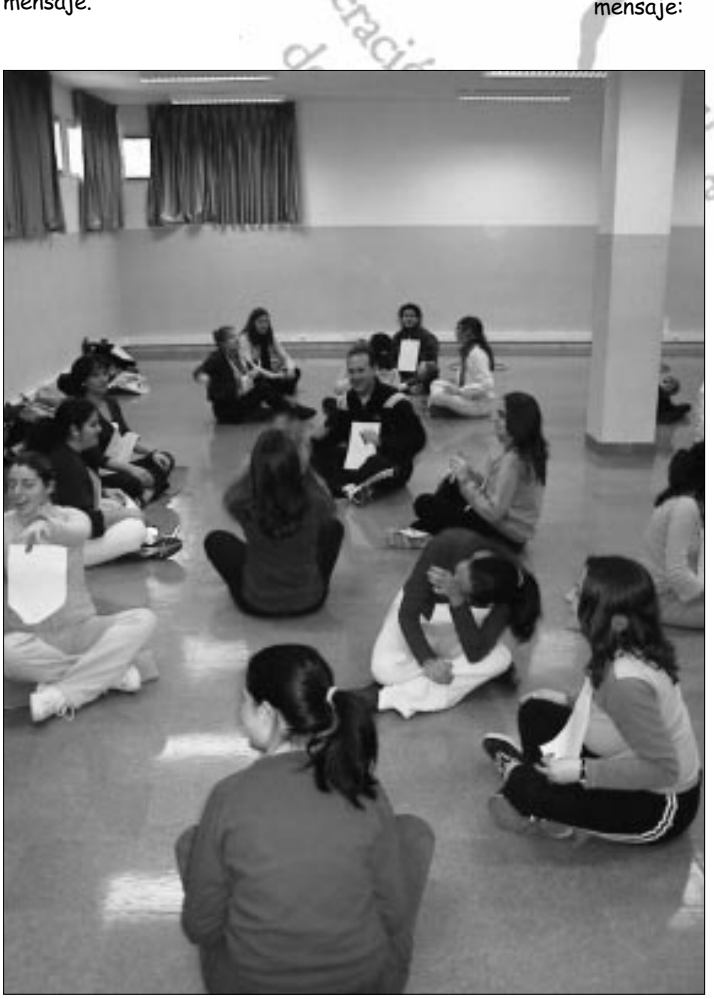

\section{La comunicación paraverbal}

Como hemos expresado con anterioridad, no sólo es reciso dominar la palabra con todo lo que ello conlleva sino que, además, hemos de ser capaces de controlar todos aquellos fenómenos vocales que acompañan a la voz, tales como las calidades de la voz (altura, timbre duración y volumen o intensidad), los sonidos y ruidos que emitimos con la misma (suspiros, risas, onomatopeyas o sonorizaciones), el ritmo de elocución o la coordinación de la respiración con el habla, entre otros, para hacer llegar con calidez y viveza el contenido del mensaje.

Por tanto, sin subestimar el potencial de la voz que constituye casi el $40 \%$ del impacto del mensaje el profesorado deberá dominar el trinomio indisoluble que se establece entre la capacidad para hablar correctamente, es decir con claridad y propiedad, y la fluidez y capacidad de convencer, de tal modo que si no existe un equilibrio entre los mismos, la competencia del orador se pondrá en entredicho tanto si comete alguna incorrección léxica de pronunciación, por muy locuaz que entonación no va acorde con el contenido del mensaje o no convence. Por ello, consideramos de interés reseñar algunas de las premisas que refuerzan el impacto del mensaje:

1. Pronunciar correctamente.

2. Jugar con el tono de la voz, al igual que o hacemos cotidianamente cuando queremos expresar un estado de ánimo o una sensación y, más concretamente, con la altura del mismo durante el mensaje, procurando variar su elevación o descenso en función del significado que se le quiera imprimir al mensaje (imperativo, interrogativo, dubitativo, etc.)

3. Atender a otros elementos de la voz como la intensidad o energía que en determinados momentos nos sirven para discernir aquellos elementos relevantes de los que no lo son en la misma medida procurando no abusar, puesto que perderían su poder de persuasión.

4. Controlar la duración de los sonidos utilizando las pausas y silencios como elementos a nuestro favor, y no como contratiempos que manifiestan duda, falta de memoria o léxico reducido por no encontrar las palabras adecuadas, que nos permiten: ocultar el nerviosismo (parar para respirar, beber agua, etc.), interactuar con el receptor (al esbozar una sonrisa o ejecutar una mueca), hacernos entender (e silencio le confiere un cierto peso a eso que acabamos de decir), hacernos oír (a atraer la atención del receptor sumamente útil cuando queremos que alguien se calle y escuche), concluir una frase, pasar de un punto a otro del discurso, pensar y estructurar las ideas que vamos a 
Retos. Nuevas tendencias en

Educación Física, Deporte y Recreación

2002, $n^{\circ} 3, p p .37-43$ exponer a continuación, 0 simplemente, tomarnos un respiro.

5. No olvidar que la entonación y el estado emocional del hablante son fieles aliados, de tal manera que, en múltiples ocasiones, lo que nos molesta 0 satisface no son las pala brasensí, sir se le infic el educador se plantee. como una de sus principales responsabilidades controlar su estado de ánimo para que no af negativamente alumnado.

6. Evitar en la medida de lo posible, los circunloquios (emplear grupos de palabras en lugar de palabras únicas), las muletillas (¿vale?, ¿eh?, etc.), así como la elevación desmesurada del tono de voz.

7. No olvidar la premisa que todo docente debe respetar y que dice que "si se maneja bien la respiración, se domina la voz".

\section{El lenguaje del cuerpo - la comunicación corporal}

El estudio del lenguaje del cuerpo se podría desglosar en multitud de elementos, casi tantos como los que posee el propio cuerpo, pero no es menos cierto que, tal y como apunta Birdwhistell (1979), precursor de la quinésica o ciencia que estudia el lenguaje del cuerpo, el análisis aislado de diferentes gestos o posturas llevados a cabo por determinadas partes del cuerpo, sin contemplar otras, y descontextualizado, pierde su significado y credibilidad.

Por ello, hemos considerado más conveniente analizar a grandes rasgos el potencial comunicativo y expresivo que posee el cuerpo, no sólo en lo que al profesorado se refiere sino también al continuo feed-back que el alumnado, atendiendo a los gestos y movimientos que realizan dentro de los cuales destacamos como más relevantes el poder de la mirada y las expresiones faciales, las posturas que adoptan y el contacto corporal que mantienen, entre otros.

4.1. Los gestos y movimientos. Al analizar este aspecto estamos atendiendo principalmente al carácter más dinámico que muestra el emisor durante el acto comunicativo ya que, sin duda, sería muy de extrañar que éste se comportara como una estatua, sin que se cuerpo se moviera para nada o como un robot cuya cara fuera inexpresiva. Evidentemente, en el proceso de comunicación se transmiten una serie de ideas que, de alguna manera, deben ser sentidas y vividas para que lleguen con más fuerza al receptor; no obstante, está comprobado que la
ISSN edición impresa : 1579-1726

40 RETOS. Nuevas tendencias en Educación Física, Deporte y Recreación 


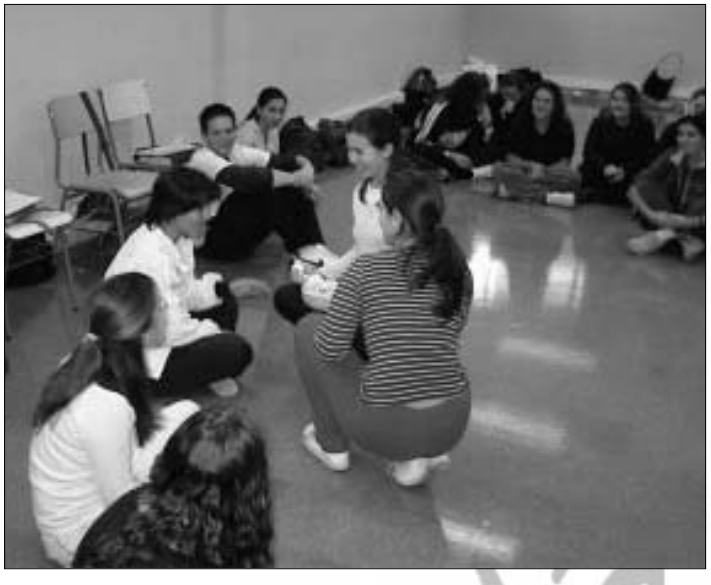

Reconocer en la mirada al elemento con mayor potencial comunicativo y expresivo del que disponemos, asignándoles distintas funciones como la de refuerzo (positivo o negativo), de control, con respecto a los niveles de comprensión y atención, y la de regulación, desde el momento en el que sólo con mirar, se puede implicar al alumnado a participar en el acto comunicativo sin necesidad de recurrir a la palabra.

Utilizar las expresiones faciales en las que intervienen la boca, los ojos y las cejas, manifestando una actitud amistosa que nos ayude a empatizar más y mejor con el alumnado, aunque, en ocasiones, la reprobadora sea necesaria para corregir ciertas comportamienreprobadora sea necesaria para corregir ciertas comportamien-
tos en clase.

Procurar mirar, en la medida de lo posible, de manera individualizada realizando un recorrido espacial con la misma, de tal modo que todo el alumnado se haga visible, teniendo en cuenta que el sentirse mirado induce a una cierta predisposición positiva por parte del alumnado, mientras que lo contrario, podría producir una sensación de indiferencia, ignorancia o rechazo. Por otro lado, no debemos olvidar aun incluyendo la mirada como un refuerzo comunicativo, que si ésta se prolonga demasiado, puede resultar incómo$\mathrm{da}$, molesta e incluso, producir una cierta ansiedad.

- Yen definitiva, recurrir más a los gestos y movimientos que transmiten actitudes de afecto, apoyo, seguridad y receptividad, evitando, en la medida delo posible, los de desprecio, amenaza, indiferencia, antipatía, y desaprobación, sin olvidarnos de esa capacidad para observar el continuo feedback que, a su vez, el alumnado también transmite a través de sus movimientos y gestos.

4.2. Las posturas corporales. Las posturas que adoptamos con el cuerpo se caracterizan por ser uno de los elementos no verbales más fáciles de observar e interpretar, no sólo por su carácter estático sino por las posibilidades que nos brindan de prolongarse en el tiempo: además, están estrechamente vinculadas a los estados emocionales, de tal forma que posturas más abiertas denotan un cierto entusiasmo y optimismo, y las más cerradas, una cierta tristeza o pesimismo, hasta tal punto, que hay quien afirma que las actitudes posturales nos hablan del pasado de las personas. Independientemente de esto, lo que sí es una realidad es que en el proceso comunicativo, los distintos interlocutores reciben continuamente un mensaje implícito en función de las posturas que adoptan a lo largo del mismo, y que su interpretación estará sujeta principalmente a dos factores: la orientación y la actitud corporal. Con respecto al primero, la orientación total del cuerpo o de alguna de sus partes nos pueden indicar, el grado de inclusión que se pretende mantener con las personas que participan en la comunicación (inclusión-exclusión), la relación que nos une (orientaciones de frente, de lado o en paralelo) y, en ocasiones, el grado de acuerdo que se establece entre las mismas (posiciones de congruencia o incongruencia) (Scheflen, A., 1976). Atendiendo al segundo, la actitud del cuerpo adoptando posiciones corporales más abiertas, cerradas, hacia delante 0 hacia atrás, así como todas aquellas que resultan al modificar alguno de sus segmentos corporales, nos transsus segmentos corporales, nos transno a la predisposición, favorable o no, de los interlocutores. Concretamente, en el caso del profesorado, queremos resaltar la importancia de este tipo de lenguaje corporal precisamente porque, en demasiadas ocasiones, su alta carga comunicativa se desenvuelve dentro de un proceso involuntario e inconsciente que nos impide actuar con cautela y prestar atención a las siguientes pautas de actuación:

a las siguientes pautas de actuación: la totalidad del alumnado o al grupo concreto al que nos estemos dirigienconcreto al que nos estemos dirigiendo darle la espalda puesto que ello se podría interpretar como desaprobación, desprecio o indiferencia.

Darle prioridad a las orientaciones frontales más que a las paralelas 0 en ángulo, puesto que favorecen y facilitan el proceso comunicativo.

- Adoptar durante la transmisión del mensaje posturas abiertas que reflejen un cierto ánimo, entusiasmo y confianza, así como posturas hacia delante que denoten atención receptividad $e$ interés.

Evitar determinadas posturas cor porales durante la intervención de receptor que pueden interpretarse negativamente, como por ejemplo cruzar los brazos en actitud distante o de enfado, taparse la boca con las manos como muestra de desacuerdo o sostenerse la cara con las manos en señal de aburrimiento.

Estar muy alerta a las continuas posturas que a su vez nos transmite el alumnado, utilizando los recursos necesarios para restablecer, en un momento dado, la sintonía entre la orientación y actitud del emisor y la del receptor.

4.3. El contacto corporal. En general, el contacto físico es un recurso comu- 
nicativo que raramente se utiliza para reforzar el mensaje transmitido y que, sin embargo, tal y como apuntan diferentes investigaciones, es uno de los estímulos que más positivamente valora el alumnado sobre todo en las primeras etapas educativas. Y es que, aunque el contacto físico varía en función del contexto, de la edad, de las relaciones que se establecen entre las personas que se comunican, del sexo del alumnado y del profesorado, o de la personalidad, no cabe ninguna duda de que una palmadita a tiempo en la espalda, puede ser uno de los mejores vehículos de transmisión, con un ahorro considerable de energía. Sin embargo, el factor que más condiciona la comunicación táctil se refiere a la cultura, y más concretamente, a las represiones sociales que se asumen tácitamente cuando nos incorporamos a la misma (por ejemplo, en la cultura árabe, el contacto corporal, incluso entre hombres, surge de una manera mucho más natural y menos represiva que en la anglosajona), por lo que en nuestro análisis, no debemos obviar dicho factor y actuar con una cierta cautela para no ser malinterpretados. Fundamentalmente, los elementos que caracterizan al contacto corporal se refieren a la duración, intensidad y zona corporal de contacto, sin olvidarnos de que en todos y cada uno de los casos, estamos relacionando el lenguaje corporal con el uso del espacio je corporal con el uso del espacio concretamente con el nal o kinesfera, como elementos indisociables es trechamente vinculados en el proceso comunicativo. Y es que, evidentemente, para establecer un contacto corporal se precisa, por un lado, de una cercanía física y, por otro, y lo que es más importante de una aprobación por parte del que lo recibe. Por lo tanto, en el ámbito educativo planteamos las siguientes propuestas de intervención:

No dejar que los condicionantes sociales inhiban la capacidad que tiene el ser humano de comunicarse a través del tacto, otorgándole de nuevo el valor que se merece por lo que abogamos por una mayor presencia de contactos físicos en el ámbito educativo, lo cual no nos eximirá de actuar con una cierta cautela, y variar la intensidad, duración y zona corporal de contacto en función de la etapa educativa y del sexo del profesorado y del alumnado; ello nos conducirá a actuaciones muy diversas, atendiendo al contexto y al momento oportuno, que se traducen en una caricia en la cara, un apretón de manos, una brazo alrededor de los hombros o un chocar los cinco.

No olvidar que en las primeras etapas educativas, el alumnado busca la aprobación del profesorado a través del contacto corporal que mantiene con el mismo.

Comportarnos con naturalidad a la hora de interactuar corporalmente sin que ello resulte demasiado forzado o intencionado en exceso, jugando con la capacidad que el grupo-clase tendrá, a posteriori, de imitar determinados comportamientos.
Al hilo de lo anterior, manifestarnos respetuosos con aquellas personas que no aceptan con naturalidad el contacto corporal, asumiendo las diferentes formas que tenemos de defender nuestro espacio más íntimo y de comunicarnos con los demás.

Observar los comportamientos afectivos o agresivos que el alumnado mantiene entre sí como un indicador más del contexto en el que se desenvuelve, así como de la personalidad que le caracteriza.

\section{RETOS. Nuevas tendencias en Educación Física, Deporte y Recreación}


Al hilo de lo expresado anteriormente, el profesorado debe estar muy atento a todas aquellas manifestaciones de invasión y violación producidas en el aula, puesto que éstas le ofrecerán una información ciertamente valiosa acerca de la dinámica del grupo, así como de las características del alumnado perteneciente al mismo.

Distribuir al grupo-clase por el espacio en forma de herradura o medio círculo, siempre que los elementos lo permitan, para favorecer el contacto visual entre profesor-alumnos y alumnos entre sí.

- En el caso de que nos enfrentáramos a aulas cuyos asientos se mantienen fijos con una distribución tradicional en filas y columnas, entonces resultará interesante recordar que si entendemos por "zona de acción preferente" o "zona activa" (desde la primera fila hasta aproximadamente la mitad de las filas que componen el aula, convergiendo hacia el centro formando un triángulo), aquélla en la que se producen las mayores interacciones entre el profesorado y el alumnado, ésta podrá pasar a convertirse en y el alumnado, ésta podrá pasar a convertirse en fesor modifique su posición y se mueva por el aula (Camacho, S. y Sáenz, O., 2000)

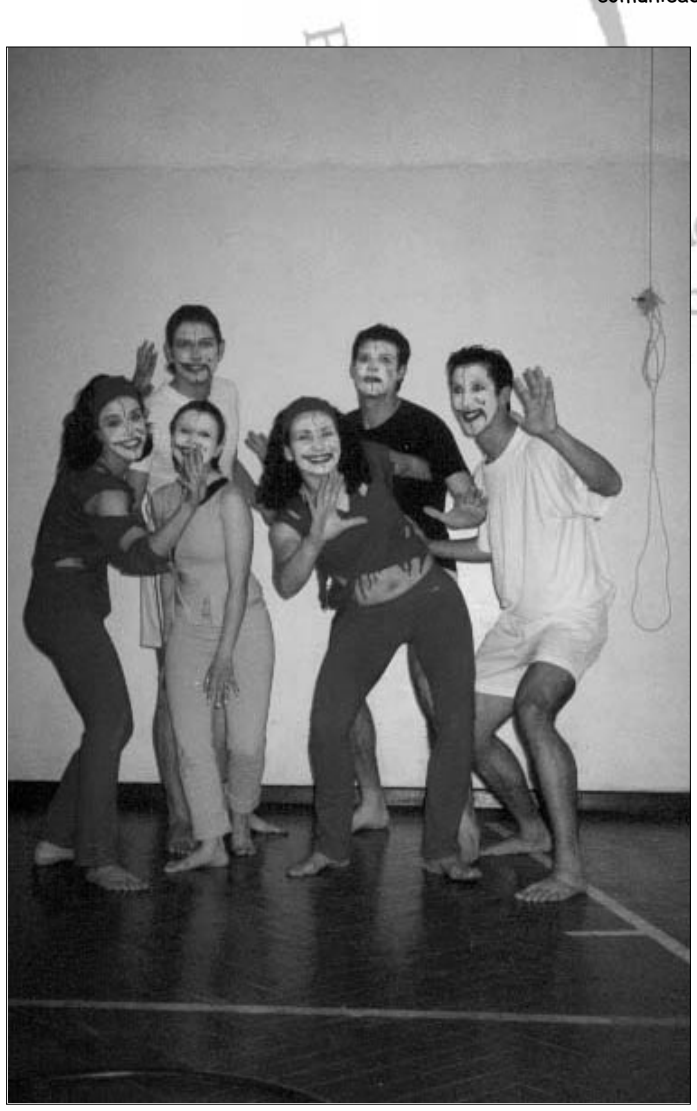

Valorar los efectos de la proximidad del profesorado con respecto al alumnado como uno de los elementos que nos puede indicar las relaciones afectivas que se establecen entre ambos (satisfacción o temor ante la proximidad del profesorado).

- Utilizar los movimientos del profesorado por el aula para activar la atención del alumnado permaneciendo en las proximidades de los que se mantienen más despistados.

- Recurrir a los elementos audiovisuales y recursos didácticos más diversos para hacer mucho más atractivas las sesiones, proponiendo al alumnado que colabore en la elaboración de los mismos, a la vez que contemplamos la posibilidad de que éstos se expongan en el aula como una prueba más de proceso de enseñanza-aprendizaje ("huellas de acción").

Para terminar, nos gustaría concluir con la idea de que, tal y como hemos analizado, el proceso de comunicación es ciertamente complejo y son muchas las habilidades y técnicas de observación y categorización que el profesorado debe dominar para llegar a ser un buen comunicador, por lo que no debemos dejar de la mano de la intuición o de la experiencia diaria en el aula, un proceso de formación específico y necesario que el profesorado, incluso sin ser consciente del valor del mismo, demanda su quehacer diario a gritos, pero en silencio.

\section{Bibliografía}

Birdwhistell, R. L. (1979). El lenguaje de la expresión corporal. Ed. Gili. Barcelona.

Camacho, S. y Sáenz, O. (2000). Técnicas de comunicación eficaz para profesores y formadores. Ed. Marfil. Alcoy.

Fast, J. (1998). El lenguaje del cuerpo (edición 14). Ed. Kairós. Barcelona.

Forner, A. (1987). La comunicación no verbal. Actividades para la escuela. Ed. Graó. Barcelona.

Knapp, M. (1980). La comunicación no verbal. El cuerpo y el entorno. Ed. Paidós. Barcelona.

Laferrière G. (1997). La dramatización como herramienta didáctica y pedagógica. Ed. Naque. Ciudad Real.

Larousse (2000). Expresión oral. Hablar bien en público. Ed. Larousse. Barcelona.

Mehrabian, A. (1972). Non-verbal Communication. Aldine-Atherton.Chicago.

Nierenberg, G. y Gschwander, G. (1989). The non-verbal selling power. Ed. Negociation Institute. OCDE.

Scheflen, A. (1976). El lenguaje del cuerpoy el orden social. Ed. Diana. México. 